\title{
Acidic Tumor pH-Responsive Nanophotomedicine for Targeted Photodynamic Cancer Therapy
}

\author{
Wooram Park, Sin-jung Park, Heejun Shin, and Kun Na \\ Center for Photomedicine, Department of Biotechnology, The Catholic University of Korea, \\ Bucheon-si, Gyeonggi-do 14662, Republic of Korea \\ Correspondence should be addressed to Kun Na; kna6997@catholic.ac.kr
}

Received 22 January 2016; Accepted 16 March 2016

Academic Editor: Gang Liu

Copyright (C) 2016 Wooram Park et al. This is an open access article distributed under the Creative Commons Attribution License, which permits unrestricted use, distribution, and reproduction in any medium, provided the original work is properly cited.

An acidic tumor $\mathrm{pH}$-responsive nanophotomedicine ( $\mathrm{pH}-\mathrm{NanoPM})$ for targeted photodynamic therapy (PDT) was demonstrated herein. The $\mathrm{pH}-\mathrm{NanoPM}$ was prepared with a size of $\sim 110 \mathrm{~nm}$ by self-assembly of a $\mathrm{pH}$-responsive polymeric photosensitizer ( $\mathrm{pH}-$ PPS) consisting of $\mathrm{pH}$-cleavable methoxypolyethylene glycol ( $\mathrm{pH}-\mathrm{C}-\mathrm{mPEG})$. Because the $\mathrm{pH}-\mathrm{C}-\mathrm{mPEG}$ can be detached from the nanoparticles by hydrolysis of the benzoic-imine group at the $\mathrm{pH}$ of an acidic tumor ( 6.5), the particle size and surface charge of the $\mathrm{pH}-\mathrm{NanoPM}$ were changed along with the environmental $\mathrm{pH}$ condition. After detachment of the $\mathrm{pH}-\mathrm{C}-\mathrm{mPEG}$, the $\mathrm{pH}$ NanoPM particles became positively charged $(+18.67 \pm 1.95 \mathrm{mV})$ due to exposure of primary amine groups and decreased to a size of $\sim 40 \mathrm{~nm}$. From in vitro cellular experiments with HeLa human cervical cancer cells, the $\mathrm{pH}$-NanoPM exhibited enhanced cellular internalization at acidic tumor $\mathrm{pH}$ compared to normal $\mathrm{pH}$, which led to a significant cancer cell killing effect. These results suggest that this system has the potential to be used as a new class of nanophotomedicine for targeted photodynamic cancer therapy.

\section{Introduction}

Over the past several decades, photodynamic therapy (PDT) has been a prospective approach for cancer treatment [13]. PDT is based on the administration of a photosensitizer (PS) and irradiation of local tumor site with appropriate light wavelength [4]. Under light irradiation, the excited PS generates cytotoxic reactive oxygen species (ROS), such as singlet oxygen or free radicals, which led to serious cell damage [5]. However, not sufficient therapeutic efficacy and side effect due to nonspecificity of PSs have been major concerns for their clinical application [6-8].

Given that reason, various types of nanotechnologybased PSs have been developed to overcome the limitations of existing PSs [9-11]. More recently, stimulus-triggered PSs have emerged to achieve higher targeting efficiency and reduce systemic toxicity [11-13]. Because $\mathrm{pH}$ of the tumor extracellular region is slightly more acidic $(\sim \mathrm{pH} 6.5)$ than the $\mathrm{pH}$ of normal region ( $\sim \mathrm{pH} 7.4)$ [14-16], delivery system based on $\mathrm{pH}$-responsiveness has been actively researched as a promising tumor targeting strategy.
Here, we demonstrate an acidic tumor $\mathrm{pH}$-responsive nanophotomedicine ( $\mathrm{pH}-\mathrm{NanoPM}$ ) for effective cancer treatment. The pH-NanoPM was prepared by self-assembly of a $\mathrm{pH}$-responsive polymeric PS (pH-PPS, Figure 1). The pH-PPS was synthesized via a three-step process (Figure 2(a)). First, $\mathrm{pH}$-cleavable methoxypolyethylene glycol (pH-C-mPEG) was synthesized by incorporation of 4-formylbenzoic acid $[17,18]$. Second, the pH-C-mPEG was conjugated with branched polyethylenimine (bPEI). Finally, a PS was introduced by a carbodiimide reaction [19]. The newly synthesized $\mathrm{pH}-\mathrm{NanoPM}$ was formed as stable micellar nanoparticles at physiological pH (i.e., pH 7.4 in normal tissues). However, the particle size and surface charge of the $\mathrm{pH}-\mathrm{NanoPM}$ particles were changed by cleavage of the pH-C-mPEG molecules in response to acidic environments (e.g., $\sim \mathrm{pH}$ 6.5 in tumor tissues). Following pH-C-mPEG cleavage, the $\mathrm{pH}-\mathrm{NanoPM}$ particles became positively charged due to the exposure of the primary amine groups in bPEI. Given the fact that the cellular membranes are negatively charged, the positively charged nature of the $\mathrm{pH}$-Nano PM particles at acidic tumor $\mathrm{pH}$ will increase their internalization into 


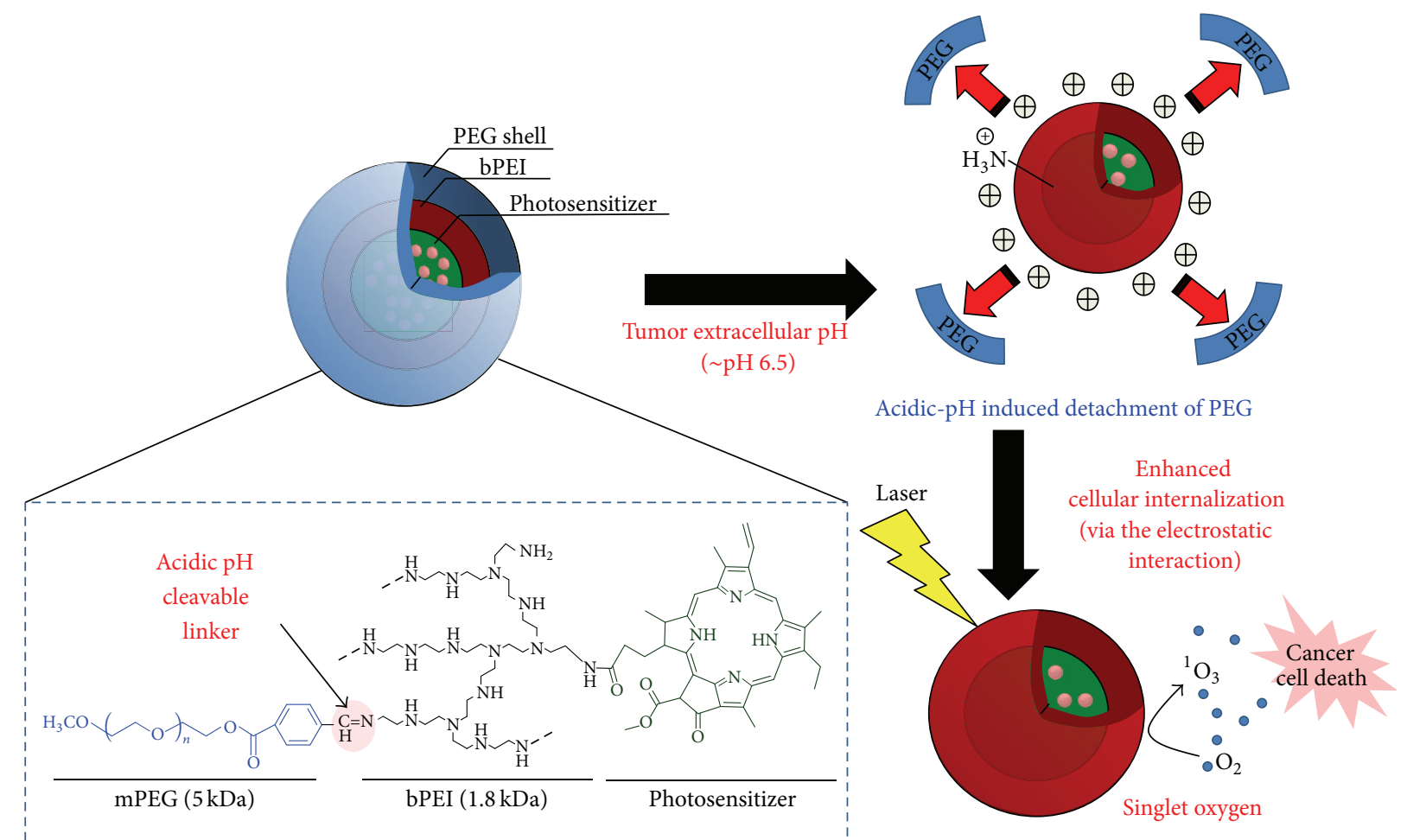

Photodynamic cancer therapy

FIGURE 1: Schematic illustration of the acidic tumor $\mathrm{pH}$-responsive nanophotomedicine ( $\mathrm{pH}-\mathrm{NanoPM}$ ).

cancer cells and therefore enhance their therapeutic effectiveness.

\section{Materials and Methods}

2.1. Materials. Methoxypolyethylene glycol (mPEG, $5 \mathrm{kDa}$ ), 4-formylbenzoic acid, dicyclohexyl carbodiimide (DCC), 4-(dimethylamino) pyridine (DMAP), N-hydroxysuccinimide (NHS), methylthiazolyldiphenyl-tetrazolium bromide (MTT), 9,10-dimethylanthracene (DMA), fluorescamine, pyrene, dichloromethane (DCM), and N,N-dimethylformamide (DMF) were purchased from Sigma-Aldrich (Yongin, Republic of Korea). Pheophorbide-a (PPb-a) was obtained from Frontier Scientific (Logan, UT, USA). Branched polyethylenimine (bPEI, $1.8 \mathrm{kDa}$ ) was purchased from Alfa Aesar (Ward Hill, MA, USA).

2.2. Synthesis of the $p H$-PPS. The $\mathrm{pH}$-PPS was synthesized via a three-step process as follows. First, $\mathrm{pH}-\mathrm{C}-\mathrm{mPEG}$ was synthesized by a modified version of a previously reported procedure $[17,18]$. Typically, 4-formylbenzoic acid $(0.6 \mathrm{~g}, 4$ millimolar), DCC (1.7 g, 8 millimolar), and DMAP (1.0 g, 8 millimolar) were added to a solution of mPEG (2 g, 0.4 millimolar) in DMF $(20 \mathrm{~mL})$. After stirring for $24 \mathrm{~h}$, the solution was filtered and precipitated in diethyl ether $(0.2 \mathrm{~L})$. The product was dried in vacuo at room temperature for $6 \mathrm{~h}$. Second, to synthesize pH-C-mPEG conjugated bPEI, bPEI $(0.2 \mathrm{~g}, 0.33$ millimolar) was dissolved in $10 \mathrm{~mL}$ of $\mathrm{DMF}$ and
pH-C-mPEG (1.7 g, 0.11 millimolar) dissolved in $10 \mathrm{~mL}$ of DMF was added. The mixture was stirred and heated to $40^{\circ} \mathrm{C}$ for $4 \mathrm{~h}$ and precipitated in cold diethyl ether $(0.2 \mathrm{~L})$. The product was dried in vacuo at room temperature for $6 \mathrm{~h}$. The formation of $\mathrm{pH}-\mathrm{C}-\mathrm{mPEG}$ conjugated bPEI was verified by ${ }^{1} \mathrm{H}-\mathrm{NMR}$. The ${ }^{1} \mathrm{H}-\mathrm{NMR}$ spectra were measured in $\mathrm{D}_{2} \mathrm{O}$ at room temperature using a Bruker NMR Spectrometer (Bruker, Germany) at $300 \mathrm{MHz}$. Finally, to incorporate PS into the $\mathrm{pH}-\mathrm{C}-\mathrm{mPEG}$ conjugated bPEI, a mixture of $\mathrm{PPb}$ a (6.96 mg, 11.59 micromolar), DCC (3.59 mg, 17.39 micromolar), and NHS (2.00 mg, 17.39 micromolar) was dissolved in $5 \mathrm{~mL}$ of DMF and stirred for $3 \mathrm{~h}$. Then, the solution was added dropwise into a solution of $\mathrm{pH}-\mathrm{C}-\mathrm{mPEG}$ conjugated bPEI $(0.2,11.59$ micromolar) with $5 \mathrm{~mL}$ of DMF, and the mixture was stirred for $24 \mathrm{~h}$ at room temperature. To purify the conjugates, the reaction solution was poured into $0.2 \mathrm{~L}$ of cold diethyl ether. This step was repeated three times and the final product was obtained followed by drying in vacuo at room temperature for $6 \mathrm{~h}$. The $\mathrm{PPb}-\mathrm{a}$ content of the $\mathrm{pH}-\mathrm{PPS}$ was measured using UV/Vis spectroscopy [20].

2.3. Preparation of the $p H-N a n o P M$. The $\mathrm{pH}-\mathrm{NanoPM}$ was prepared by a dialysis method. Briefly, the pH-PPS (10 mg) was dissolved in $5 \mathrm{~mL}$ of DMSO and dialyzed for $24 \mathrm{~h}$ against $\mathrm{NaOH} / \mathrm{Na}_{2} \mathrm{~B}_{4} \mathrm{O}_{7}$ buffer using a dialysis membrane (Molecular weight cut-off (MWCO), $1 \mathrm{kDa}$, Spectrum Laboratories, Rancho Dominguez, CA, USA). 


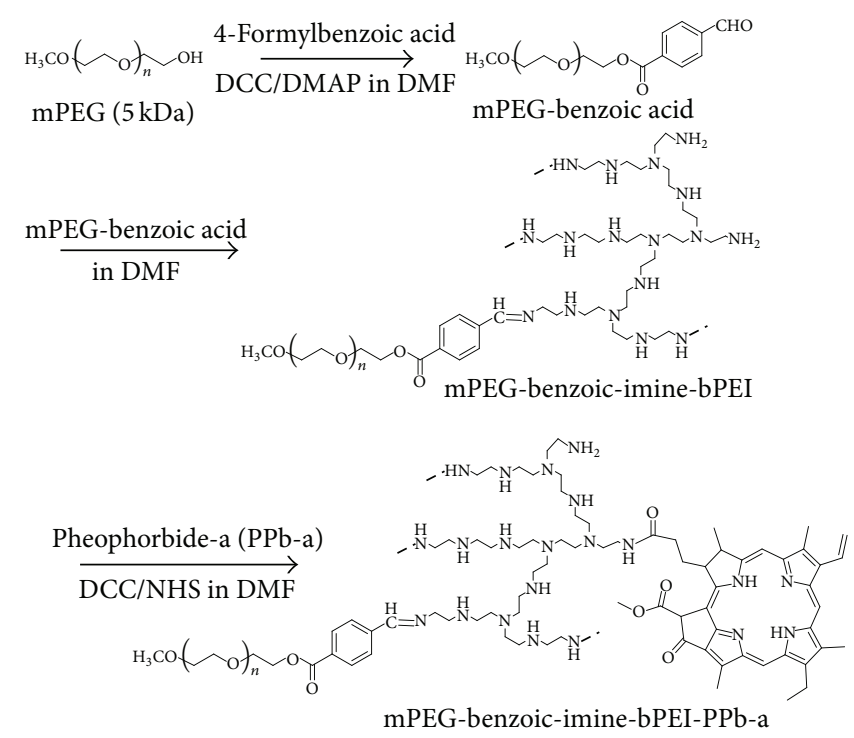

(a)

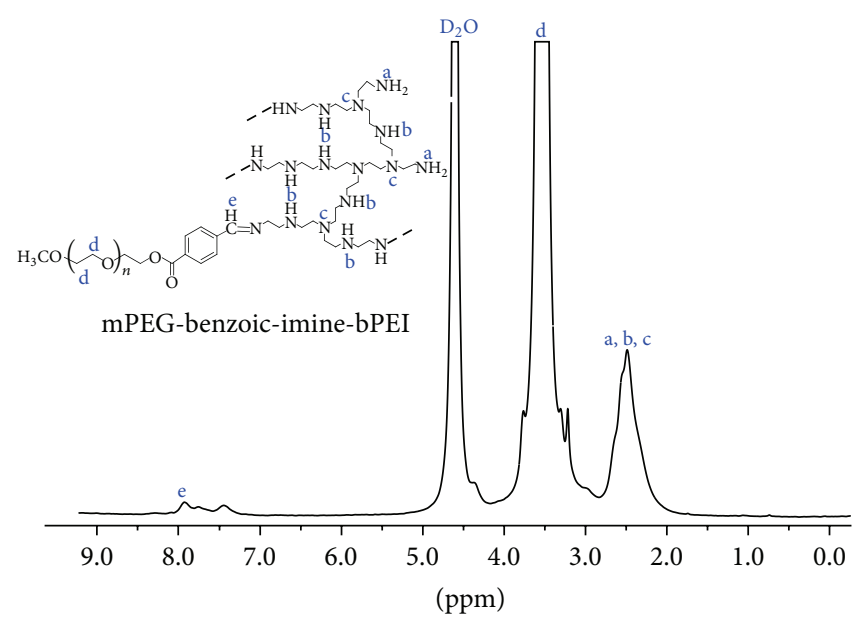

(b)

FIGURE 2: Chemical synthesis of the $\mathrm{pH}$-responsive polymeric photosensitizer (pH-PPS). (a) Synthesis of the pH-PPS and (b) ${ }^{1} \mathrm{H}-\mathrm{NMR}$ analysis of mPEG-benzoic-imine-bPEI in $\mathrm{D}_{2} \mathrm{O}$.

2.4. Characterization of the $p H-N a n o P M$. The particle size distribution and zeta-potential of the $\mathrm{pH}-\mathrm{NanoPM}$ were determined at different $\mathrm{pH}$ values ( $\mathrm{pH} 7.4$ and 6.5) using DLS (Zetasizer Nano ZS, Malvern Instruments Ltd., UK). All the DLS experiments were performed at $25^{\circ} \mathrm{C}$ in aqueous solution with $1 \mathrm{mg} / \mathrm{mL}$ of concentration.

\subsection{Measurement of Critical Aggregation Concentration} $(C A C)$. The CAC value of the $\mathrm{pH}-\mathrm{NanoPM}$ was calculated using pyrene $[21,22]$. Briefly, the pyrene was dissolved into acetone with concentration of $6.0 \times 10^{-2} \mathrm{M}$, and then the solution was added to distilled water to yield a pyrene concentration of $12.0 \times 10^{-7} \mathrm{M}$. To remove remaining acetone, the solution was stirred for $6 \mathrm{~h}$ at room temperature. Then, the pyrene solution was mixed with solutions of the $\mathrm{pH}-\mathrm{NanoPM}$ in different concentrations and incubated overnight. The following day, the fluorescence intensities of the mixtures were detected using a fluorescent spectrometer (RF-5301PC, Shimadzu, Japan).

2.6. Measurement of Singlet Oxygen Generation (SOG). The $\mathrm{pH}-\mathrm{NanoPM}(\mathrm{PPb}-\mathrm{a}, 1.5 \mu \mathrm{g} / \mathrm{mL})$ was dissolved in DMF and mixed with DMA stock solutions $\left(6.0 \times 10^{-2} \mathrm{M}\right)$ to give a final concentration of 20 micromolar DMA. Following stirring for $10 \mathrm{~min}$ at room temperature, samples containing the $\mathrm{pH}$ NanoPM and DMA were irradiated with a light intensity of $5 \mathrm{~mW} / \mathrm{cm}^{2}$ using a $670 \mathrm{~nm}$ laser source (fiber-coupled laser system, LaserLab, Republic of Korea).

2.7. Quantitative Measurement of the Exposed Amine Groups in the $\mathrm{pH}$-NanoPM. The $\mathrm{pH}$-NanoPM $(1 \mathrm{mg})$ was dissolved in deionized water $(1 \mathrm{~mL})$. The resulting solution $(100 \mu \mathrm{L})$ was mixed with PBS $(1 \mathrm{~mL}, 150 \mathrm{mM})$ at $\mathrm{pH} 7.4$ and 6.5.
This solution was incubated at $37^{\circ} \mathrm{C}$ for $6 \mathrm{~h}$ and then mixed with $20 \mu \mathrm{L}$ of fluorescamine $(2.5 \mathrm{mg} / \mathrm{mL})$ in $\mathrm{DMF}$ at room temperature for $30 \mathrm{~min}$. The fluorescence intensity of each solution was measured using a fluorescent spectrometer at excitation wavelength $365 \mathrm{~nm}$ and at emission wavelength $465 \mathrm{~nm}$.

2.8. Cell Culture and Incubation Conditions. HeLa cells were cultured in Dulbecco's Modified Eagle Medium (DMEM, $25 \mathrm{mmol} / \mathrm{L}$ glucose) equilibrated with $5 \% \mathrm{CO}_{2}$ and $95 \%$ air at $37^{\circ} \mathrm{C}$. The medium was supplemented with $10 \%$ fetal calf serum (FCS), $50 \mathrm{mg} / \mathrm{L}$ streptomycin, and $75 \mathrm{mg} / \mathrm{L}$ penicillin sulfate.

2.9. In Vitro Cellular Internalization Test. To confirm the cellular uptake of $\mathrm{pH}-\mathrm{NanoPM}$ at two different $\mathrm{pH}$ values ( $\mathrm{pH} 7.4$ and 6.5) [9], HeLa cells were seeded in a $35 \mathrm{~mm}^{2}$ cell culture dish at a density of $1.0 \times 10^{6}$ cells/dish and were cultured for $24 \mathrm{~h}$ at $37^{\circ} \mathrm{C}$ in $5 \% \mathrm{CO}_{2}$. The cells were treated with serum free (SF) medium containing the $\mathrm{pH}-\mathrm{NanoPM}$ $\left(\mathrm{PPb}-\mathrm{a}, 3.2 \times 10^{6} \mathrm{M}\right)$ for $30 \mathrm{~min}$ at $\mathrm{pH} 7.4$ or 6.5 . After that, the cells were harvested and redispersed into Dulbecco's phosphate buffer saline (DPBS, Invitrogen Corp., Carlsbad, $\mathrm{CA}, \mathrm{USA}$ ). The cellular uptake of $\mathrm{PPb}$-a was measured using a flow cytometry (Beckman, San Jose, CA, USA) and analyzed using a CXP analysis program (Beckman).

2.10. Confocal Laser Scanning Microscopy (CLSM) Analysis. To observe the cellular localization of $\mathrm{pH}-\mathrm{NanoPM}$ in HeLa cells $[9,23]$, HeLa cells $\left(1.0 \times 10^{5}\right.$ cells/well $)$ were cultured on cover slips placed in six-well plates. The following day, the cells were treated with the $\mathrm{pH}-\mathrm{NanoPM}$ for $30 \mathrm{~min}$ at $\mathrm{pH} 7.4$ or 6.5 . Then, the cells were washed with DPBS and fixed with a $4 \%$ paraformaldehyde solution. To observe 
the cells under microscope, the cells were mounted using a DAPI containing mounting solution (Fluoroshield ${ }^{\mathrm{TM}}$ with DAPI, Sigma-Aldrich, Yongin, Republic of Korea). Then, the cells were visualized using a confocal laser scanning microscope (CLSM, LSM 710 Meta; Carl Zeiss, Germany).

2.11. In Vitro Cytotoxicity Study. To confirm the PDTmediated cancer cell killing effect of the pH-NanoPM, HeLa cells were seeded in black 96-well culture plates at a density of $2.0 \times 10^{4}$ cells per well. After culturing for $24 \mathrm{~h}$, the cells were treated with the SF medium containing the $\mathrm{pH}-\mathrm{NanoPM}$ (PPb-a, $10 \mu \mathrm{g} / \mathrm{mL}$ ) and incubated for $30 \mathrm{~min}$. After that, the cells were washed with DPBS to remove remaining $\mathrm{pH}$ NanoPM in the medium and incubated with fresh complete medium. Then, the cells were irradiated using a $670 \mathrm{~nm}$ laser source $\left(3.6 \mathrm{~J} \mathrm{~cm}^{-2}\right.$, fiber-coupled laser system, LaserLab, Republic of Korea). After 24 h, the cell viability was measured using a MTT assay.

2.12. Statistical Analysis. Data are expressed as the mean \pm standard deviation (SD). Differences between values were assessed using Student's $t$-tests.

\section{Results and Discussion}

3.1. Synthesis and Preparation of the $p H-N a n o P M$. In this study, a novel $\mathrm{pH}$-responsive polymeric photosensitizer $(\mathrm{pH}$ PPS) was designed and synthesized as shown in Figure 2(a). First, pH-cleavable methoxypolyethylene glycol (pH-C$\mathrm{mPEG}$ ) was synthesized by incorporation of 4-formylbenzoic acid, which formed a benzoic-imine linkage with primary amine groups. The hydrolysis kinetics and hydrolysis bonding equilibrium of an imine bond are significantly influenced by the environmental $\mathrm{pH}[17,18,24]$. According to previous reports $[17,18]$, the benzoic-imine bond was stable at $\mathrm{pH}$ 7.4, while rapid hydrolysis was observed in acidic $\mathrm{pH}$ environments. As-synthesized pH-C-mPEG was then linked with bPEI via the benzoic-imine linkage. The successful synthesis of $\mathrm{pH}-\mathrm{C}-\mathrm{mPEG}$ conjugated bPEI was confirmed by using ${ }^{1} \mathrm{H}$ NMR analysis (Figure 2(b)). Finally, the PS, pheophorbidea $(\mathrm{PPb}-\mathrm{a})$, was conjugated with the primary amine group of the $\mathrm{pH}-\mathrm{C}-\mathrm{mPEG}$ and $\mathrm{bPEI}$ conjugates through carbodiimide coupling chemistry [20].

3.2. Characterization of the $p H-N a n o P M$. The synthesized $\mathrm{pH}-\mathrm{PPS}$ was further analyzed using a UV-Vis spectrophotometry. As shown in Figure 3(a), the UV-Vis spectra of the $\mathrm{pH}$-PPS presented dominant absorption bands at 400 and $670 \mathrm{~nm}$, which originate from the PPb-a. These results indicate that the $\mathrm{PPb}-\mathrm{a}$ molecules were successfully incorporated into the polymeric conjugates. The $\mathrm{pH}-\mathrm{NanoPM}$ was a self-assembled form of nanomicellar aggregates in aqueous solution, assembled by their amphiphilicity. To confirm the critical aggregation concentration (CAC), the fluorescence emission spectrum of pyrene was measured in different concentrations of $\mathrm{pH}$-PPS. Because the fluorescence of pyrene is influenced by environmental polarity changes, pyrene has been used to determine CAC values of amphiphilic polymers [22]. The fluorescent emission peaks of pyrene at 373 and $383 \mathrm{~nm}$ were denoted as $I_{1}$ and $I_{3}$, respectively. The $I_{1} / I_{3}$ ratio was used to measure the concentration at which the conjugates can self-assemble as nanoparticular structures. As shown in Figure 3(b), the CAC of the $\mathrm{pH}$ NanoPM was found to be $0.01 \mathrm{mg} / \mathrm{mL}$ at $\mathrm{pH} 7.4$, indicating that the stable nanoparticular structure remains above this concentration. Additionally, it is worth noting that the $\mathrm{pH}-\mathrm{NanoPM}$ exhibited good drug loading efficiency (drug loading contents (wt\%): $3.9 \pm 0.5 \%$ doxorubicin). This result indicates that the developed $\mathrm{pH}$-Nano PM can be used not only as a photomedicine but also as a drug-delivery carrier. To assess the photo-activity of the $\mathrm{pH}-\mathrm{NanoPM}$, singlet oxygen generation ability was monitored using DMA, the fluorescent intensity of which is highly quenched upon selective reaction with singlet oxygen [25]. The $\mathrm{pH}-\mathrm{NanoPM}$ dissolved in DMF solution was irradiated using a $670 \mathrm{~nm}$ laser for different lengths of time and then the amount of singlet oxygen generated was determined by the amount of DMA fluorescence quenched. As shown in Figure 3(c), the relative fluorescence intensity of DMA from the $\mathrm{pH}$ PPS solution gradually decreased with increasing exposure time with a reduction level of $\sim 40 \%$ after 3 min exposure. No significant differences in DMA reduction levels were observed between the $\mathrm{pH}-\mathrm{PPS}$ and free $\mathrm{PPb}-\mathrm{a}$, suggesting that the $\mathrm{pH}$-PPS retains the singlet oxygen generation ability after conjugation with the polymer. To determine the effect of $\mathrm{pH}$ on the $\mathrm{pH}$-cleavable linker benzoic-imine, particle size distribution changes were monitored under different $\mathrm{pH}$ conditions. The $\mathrm{pH}$-NanoPM particles were found to have a size of $\sim 110 \mathrm{~nm}$ with a narrow size distribution at $\mathrm{pH} 7.4$, the physiological $\mathrm{pH}$ of the bloodstream. The $\mathrm{pH}-\mathrm{NanoPM}$ particles were found to be smaller $(\sim 40 \mathrm{~nm})$ at $\mathrm{pH} 6.5$, the acidic tumor $\mathrm{pH}$. This indicates that the PEG molecules on the surface of $\mathrm{pH}$-NanoPM were successfully detached due to the cleavage of the benzoic-imine linker at acidic $\mathrm{pH}$.

3.3. pH-Responsive Physical Property Changes of the $p H$ NanoPM. As discussed previously, the pH-NanoPM was designed to enable detachment of the PEG shell and conversion of surface charge from negative to positive at the tumor site for efficient cellular internalization. To confirm the surface charge conversion ability of the $\mathrm{pH}-\mathrm{NanoPM}$, the zetapotential of the particles was observed under different $\mathrm{pH}$ conditions. As shown in Figure 4(a), the pH-NanoPM had a slightly negatively charged surface at physiological pH (zetapotential value $=-1.89 \pm 3.20 \mathrm{mV}$ ). In general, negatively charged nanoparticles are stable and tend not to undesirably aggregate with serum proteins in the bloodstream [9]. The surface charge of the $\mathrm{pH}-\mathrm{NanoPM}$ increased to $+18.67 \pm$ $1.95 \mathrm{mV}$ at $\mathrm{pH}$ 6.5. To further investigate the chemical cleavage of the $\mathrm{pH}$-cleavable linker, primary amine groups in the $\mathrm{pH}$-NanoPM were quantitatively measured at different $\mathrm{pH}$ values using fluorescamine which is an amine-specific fluorescent probe. The fluorescamine results (Figure 4(b)) showed that the $\mathrm{pH}-\mathrm{NanoPM}$ contains $\sim 50 \%$ free amine groups at $\mathrm{pH}$ 7.4. The primary amine contents of $\mathrm{pH}-\mathrm{NanoPM}$ increased significantly to $\sim 90 \%$ at $\mathrm{pH} 6.5$, suggesting that 


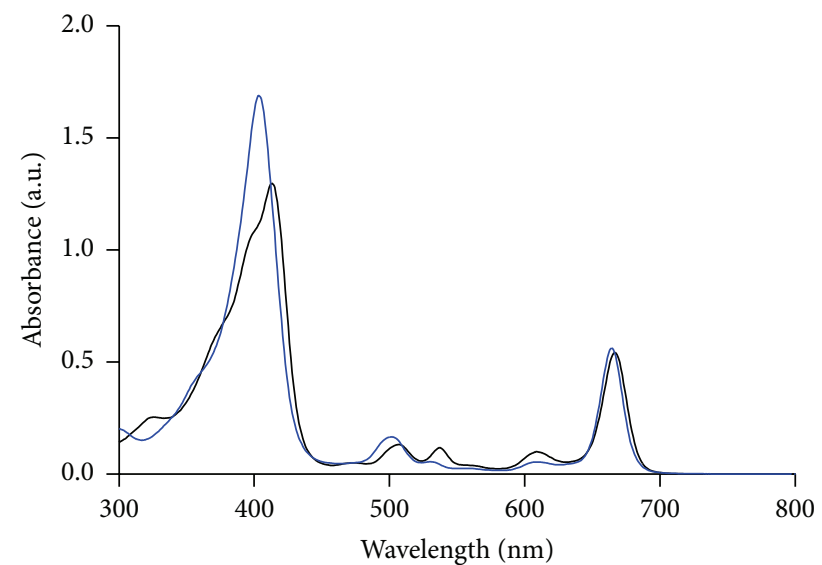

Free PPb-a - pH-PPS

(a)

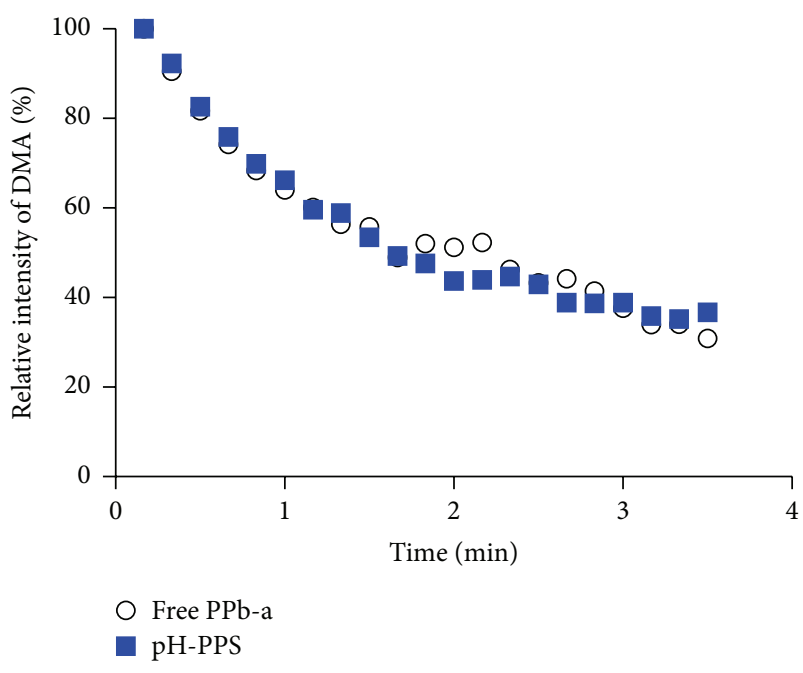

(c)

c)

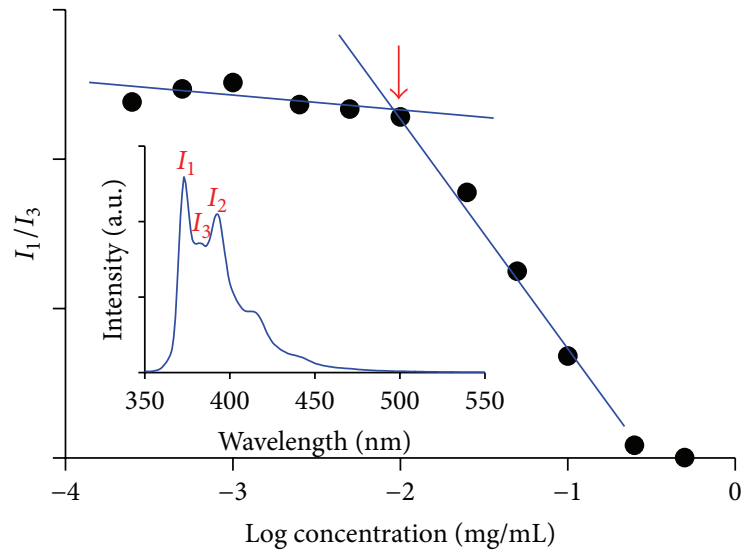

(b)

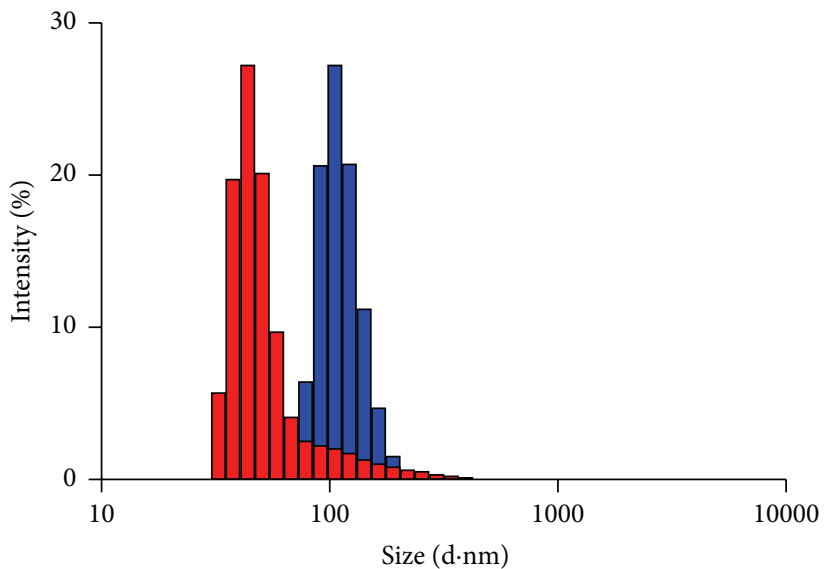

pH 7.4

pH 6.5

FIGURE 3: Physicochemical characterization of the pH-NanoPM. (a) UV-Vis absorption spectra of free pheophorbide-a (PPb-a) and pH-PPS. (b) Analysis of the critical aggregate concentration (CAC) of pH-PPS (Inset: fluorescent emission spectra of pyrene in polymer dissolved water). (c) Measurement of singlet oxygen generation of free PPb-a and pH-PPS in DMF with laser irradiation. (d) Particle size distribution of $\mathrm{pH}-\mathrm{NanoPM}$ particles at different $\mathrm{pH}$ values ( $\mathrm{pH} 7.4$ and 6.5).

the free primary amines in the $\mathrm{pH}-\mathrm{NanoPM}$ are exposed by successful cleavage of the $\mathrm{pH}$-responsive benzoic-imine linker. These results demonstrate that the PEG shells are successfully detached from the $\mathrm{pH}-\mathrm{NanoPM}$ by the cleavage of the $\mathrm{pH}$-responsive cleavable linker at acidic $\mathrm{pH}$ and that physical properties might lead to a microenvironmentspecific delivery.

3.4. $p H$-Responsive Cellular Internalization of the $p H$ NanoPM. Having demonstrated that the PEG shell on the surface of the $\mathrm{pH}-\mathrm{NanoPM}$ is capable of detachment at weak acidic $\mathrm{pH}$ and the subsequent exposure of the cationic amine groups of bPEI, the cellular internalization of the $\mathrm{pH}$ NanoPM was monitored in a cancer cell line. HeLa, a cervical cancer cell line, was used in this study. The HeLa cells were incubated with the $\mathrm{pH}-\mathrm{NanoPM}$ particles at $\mathrm{pH} 7.4$ or 6.5 , and the cellular uptake and subcellular localization of particles were determined using flow cytometry and confocal laser scanning microscopy (CLSM), respectively. According to our previous reports $[9,12]$, the $\mathrm{pH}$ change of cell media does not influence the cellular uptake behavior of nanoparticles itself. In this study, a noncleavable linker containing group was not included because their uptake behavior has already been reported $[17,18]$ : the noncleavable PEG containing micelles showed low cellular internalization behavior regardless of $\mathrm{pH}$ value change. PEG, a hydrophilic polymer, is well known to be biocompatible and nonimmunogenic and to improve pharmacokinetics $[26,27]$. For those reasons, PEG has been used to impart a steric barrier on delivery carriers resulting in reduced reticuloendothelial system (RES) uptake and enhanced blood circulation time. However, it has been reported that the physical properties of PEG also reduce 


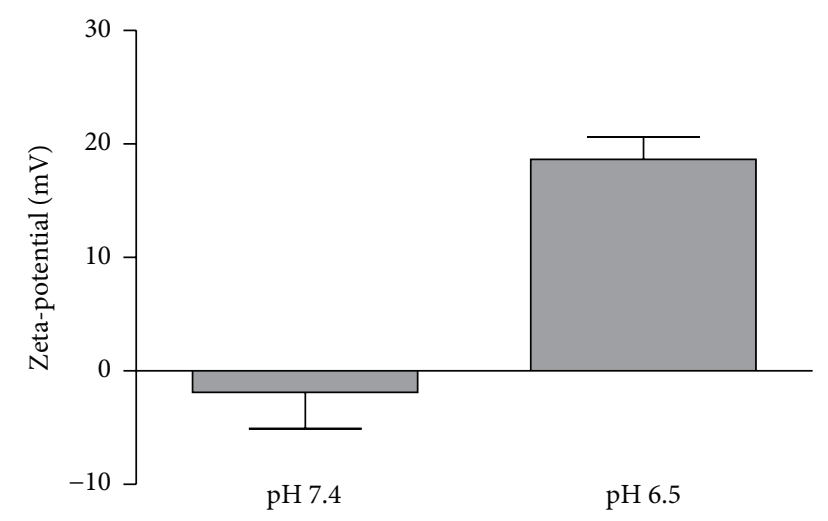

(a)

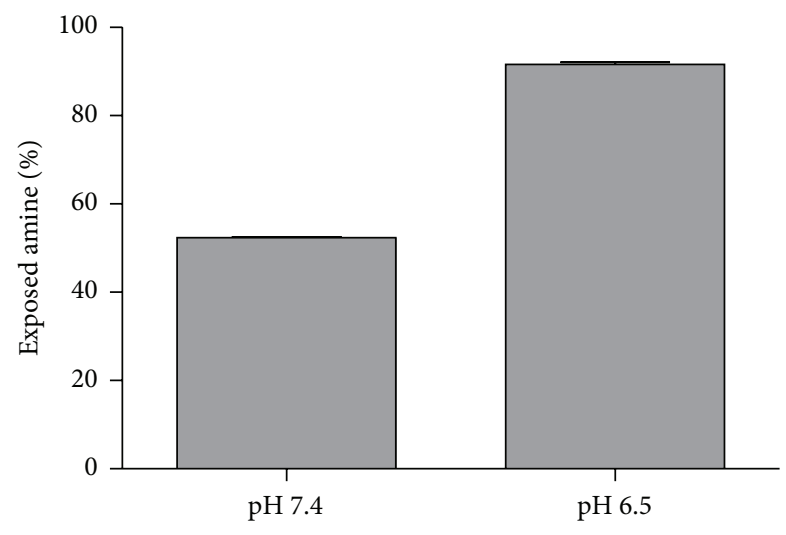

(b)

FIGURE 4: $\mathrm{pH}$-responsive physical property changes of the $\mathrm{pH}$ NanoPM. (a) Zeta-potential measurement of the pH-NanoPM at different $\mathrm{pH}$ values ( $\mathrm{pH} 7.4$ and 6.5). (b) Quantitative measurement of exposed amine groups in different $\mathrm{pH}$ values as determined by fluorescamine assay ( $\mathrm{pH} 7.4$ and 6.5).

tumor cell uptake. As shown in Figure 5(a), fewer than 6\% of $\mathrm{pH}-\mathrm{NanoPM}$ particles were internalized at $\mathrm{pH}$ 7.4, indicating that the PEG shell of the nanoparticles hinders their cellular uptake capacity. Under acidic tumor $\mathrm{pH}(\mathrm{pH}$ 6.5), much greater cellular uptake was observed $(>95 \%)$ compared to cells incubated with the particles at $\mathrm{pH}$ 7.4. This result is consistent with previous reports $[17,18]$ and suggests that the detachment of the PEG shell from the pH-NanoPM particles at $\mathrm{pH} 6.5$ led to enhanced cellular internalization of the nanoparticles for targeted cancer therapy. In addition to the uptake properties, the cellular localization of the $\mathrm{pH}-\mathrm{NanoPM}$ particles was observed by CLSM. As shown in Figure 5(b), the pH-NanoPM particles were located mainly within the cytoplasm. The signals from the $\mathrm{PPb}-\mathrm{a}$ of the $\mathrm{pH}-\mathrm{NanoPM}$ and the DAPI-stained nuclei are depicted in cyan and blue, respectively. Furthermore, Figure 5(b) clearly shows that a few $\mathrm{pH}$-NanoPM particles were delivered to nuclei as well, which is desirable for an efficient anticancer therapeutic effect.

3.5. In Vitro Cytotoxicity of $p H-N a n o P M$ at Different $p H$. After we confirmed the differential intracellular uptake of the
$\mathrm{pH}-\mathrm{NanoPM}$ under different $\mathrm{pH}$ conditions, we determined the photo-mediated anticancer therapeutic effect. HeLa cells were treated with the $\mathrm{pH}-\mathrm{NanoPM}$ at $\mathrm{pH} 7.4$ or 6.5 and were irradiated with a $670 \mathrm{~nm}$ laser $\left(3.6 \mathrm{~J} / \mathrm{cm}^{-2}, n=4\right)$. Cell viabilities at different $\mathrm{pH}$ values were measured using an MTT assay. The quantified cell viability results showed that there is a significant cell killing effect with $\mathrm{pH}-\mathrm{NanoPM}$ treatment at weak acidic $\mathrm{pH}$. As shown in Figure 6, under no laser irradiation, the $\mathrm{pH}-\mathrm{NanoPM}$ showed no cytotoxicity at $\mathrm{pH} 7.4$, suggesting the biocompatibility of the synthesized polymer. The cells treated with the particles at $\mathrm{pH} 6.5$ showed a slightly reduced level of viability, which might be due to the surface charge change of the $\mathrm{pH}-\mathrm{NanoPM}$ from negative to positive by the deshielding of the PEG layer. It is well known that positively charged nanoparticles have cytotoxicity due to their cationic charge inducing membrane damage $[28,29]$. Under laser irradiation, the $\mathrm{pH}-\mathrm{NanoPM}$ at $\mathrm{pH} 7.4$ showed faint cancer treatment efficiency with a viability of $90.12 \pm 4.44 \%$, which correlates with the reduced uptake at physiological $\mathrm{pH}$, while the cells treated with the $\mathrm{pH}-\mathrm{NanoPM}$ at $\mathrm{pH} 6.5$ and irradiation had a viability of $29.42 \pm 11.82 \%$. These results clearly demonstrate that the $\mathrm{pH}-$ mediated detachment of PEG layer of the $\mathrm{pH}-\mathrm{NanoPM}$ leads to enhanced internalization and ultimately successful photomediated cancer treatment.

\section{Conclusions}

The $\mathrm{pH}$-NanoPM presented herein was designed to respond to an acidic tumor extracellular $\mathrm{pH}$ to accomplish a targeted photodynamic cancer therapy. At weak acidic $\mathrm{pH}$, the successful cleavage of the $\mathrm{pH}$-responsive linker (i.e., benzoicimine) was confirmed by chemical analysis. Consequently, the hydrophilic PEG shell that physically hinders cellular internalization was detached from the nanoparticles, which led to a switch in the charge of the particles from negative to positive and a decrease in the size of the $\mathrm{pH}-\mathrm{NanoPM}$ particles. With these desirable properties, the $\mathrm{pH}-\mathrm{NanoPM}$ exhibited enhanced cellular internalization at acidic tumor $\mathrm{pH}$ compared to that at normal $\mathrm{pH}$, resulting in a significant cancer cell killing effect. These results suggest that this system has the potential to be used as a new class of nanophotomedicine for targeted photodynamic cancer therapy. Given the promising results of these initial in vitro studies, further demonstration is now expected to examine their therapeutic effectiveness in vivo.

\section{Competing Interests}

The authors confirm that they have no financial and personal interests in the work described.

\section{Authors' Contributions}

Wooram Park and Sin-jung Park contributed equally to this work. 


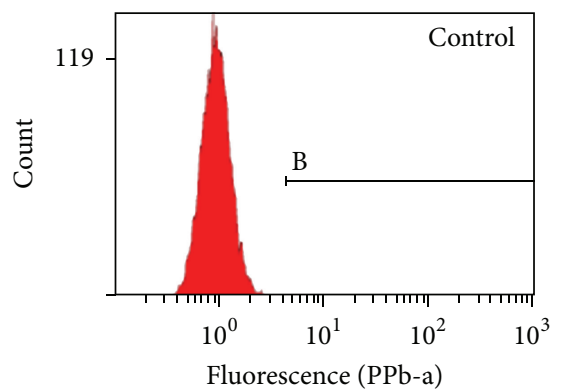

Fluorescence $(\mathrm{PPb}-\mathrm{a})$

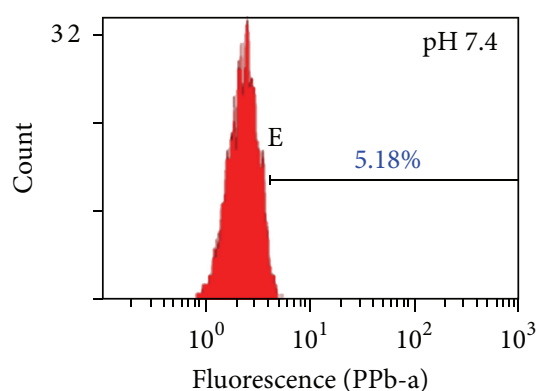

(a)
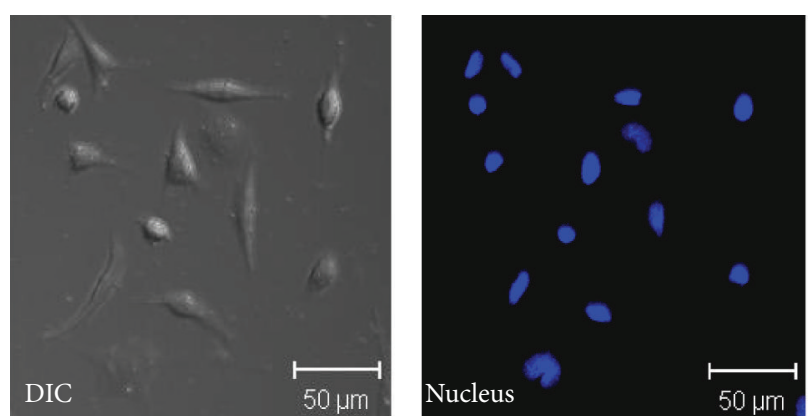
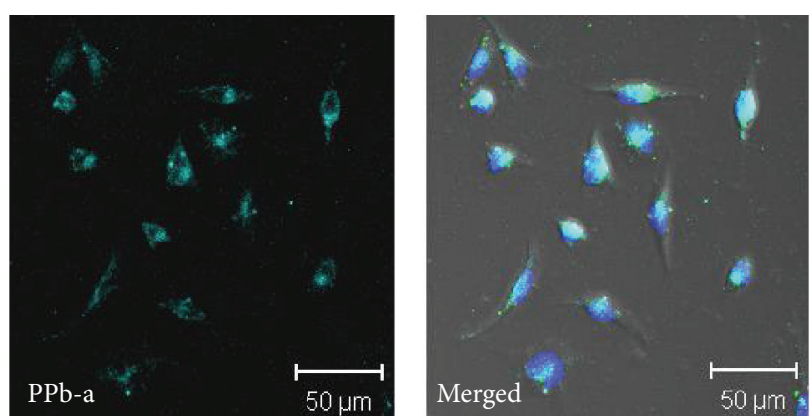

(b)

FIGURE 5: In vitro cellular internalization of the $\mathrm{pH}-\mathrm{NanoPM}$. (a) Flow cytometry quantification of the cellular internalization of the pHNanoPM at different $\mathrm{pH}$ values (pH 7.4 and 6.5). (b) Confocal microscopy image of HeLa cells treated with the pH-NanoPM (Scale bars: $50 \mu \mathrm{m})$.

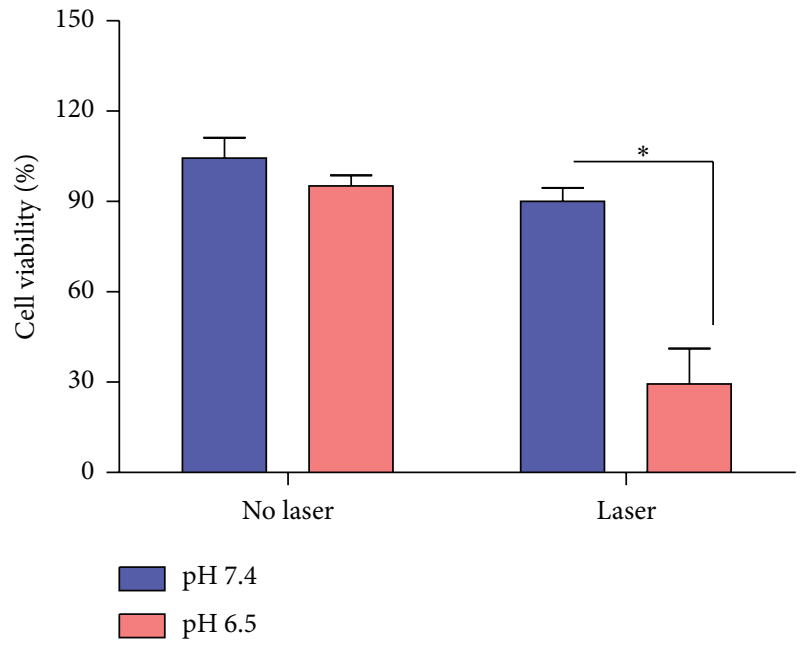

FIGURE 6: In vitro cytotoxicity test of the pH-NanoPM at different $\mathrm{pH}$ values: HeLa cells treated with the $\mathrm{pH}-\mathrm{NanoPM}$ at $\mathrm{pH} 7.4$ and 6.5 (dose of PPb-a: $1.6 \times 10^{-5} \mathrm{M}$, and laser power: $3.6 \mathrm{~J} / \mathrm{cm}^{-2}, n=4$, $\left.{ }^{*} p<0.001\right)$.

\section{Acknowledgments}

This work was supported by the Strategic Research Program (no. 2011-0028726), through the National Research Foundation of Korea (NRF) grant funded by the Korean government (MSIP).

\section{References}

[1] C. A. Robertson, D. H. Evans, and H. Abrahamse, "Photodynamic therapy (PDT): a short review on cellular mechanisms and cancer research applications for PDT,' Journal of Photochemistry and Photobiology B: Biology, vol. 96, no. 1, pp. 1-8, 2009.

[2] D. E. J. G. J. Dolmans, D. Fukumura, and R. K. Jain, "Photodynamic therapy for cancer," Nature Reviews Cancer, vol. 3, no. 5, pp. 380-387, 2003.

[3] Z. Luksiene, I. Eggen, J. Moan, J. M. Nesland, and Q. Peng, "Evaluation of protoporphyrin IX production, phototoxicity and cell death pathway induced by hexylester of 5aminolevulinic acid in Reh and HPB-ALL cells," Cancer Letters, vol. 169, no. 1, pp. 33-39, 2001.

[4] S. S. Lucky, K. C. Soo, and Y. Zhang, "Nanoparticles in photodynamic therapy," Chemical Reviews, vol. 115, no. 4, pp. 1990-2042, 2015.

[5] I. Roy, T. Y. Ohulchanskyy, H. E. Pudavar et al., "Ceramicbased nanoparticles entrapping water-insoluble photosensitizing anticancer drugs: a novel drug-carrier system for photodynamic therapy," Journal of the American Chemical Society, vol. 125, no. 26, pp. 7860-7865, 2003.

[6] Q. Peng, T. Warloe, J. Moan et al., "Distribution of 5aminolevulinic acid-induced porphyrins in noduloulcerative basal cell carcinoma," Photochemistry and Photobiology, vol. 62, no. 5, pp. 906-913, 1995.

[7] E. Reddi, "Role of delivery vehicles for photosensitizers in the photodynamic therapy of tumours," Journal of Photochemistry and Photobiology B: Biology, vol. 37, no. 3, pp. 189-195, 1997. 
[8] J. Gravier, R. Schneider, C. Frochot et al., "Improvement of meta-tetra(hydroxyphenyl)chlorin-like photosensitizer selectivity with folate-based targeted delivery. Synthesis and in vivo delivery studies," Journal of Medicinal Chemistry, vol. 51, no. 13, pp. 3867-3877, 2008.

[9] S. Jeong, W. Park, C.-S. Lee, and K. Na, "A cancer-recognizing polymeric photosensitizer based on the tumor extracellular $\mathrm{pH}$ response of conjugated polymers for targeted cancer photodynamic therapy," Macromolecular Bioscience, vol. 14, no. 12, pp. 1688-1695, 2014.

[10] M. A. Campo, D. Gabriel, P. Kucera, R. Gurny, and N. Lange, "Polymeric photosensitizer prodrugs for photodynamic therapy," Photochemistry and Photobiology, vol. 83, no. 4, pp. 958965, 2007.

[11] S. Y. Park, H. J. Baik, Y. T. Oh, K. T. Oh, Y. S. Youn, and E. S. Lee, "A smart polysaccharide/drug conjugate for photodynamic therapy," Angewandte Chemie-International Edition, vol. 50, no. 7, pp. 1644-1647, 2011.

[12] D. Ling, W. Park, S.-J. Park et al., "Multifunctional tumor pHsensitive self-assembled nanoparticles for bimodal imaging and treatment of resistant heterogeneous tumors," Journal of the American Chemical Society, vol. 136, no. 15, pp. 5647-5655, 2014.

[13] C. W. Chu, J. H. Ryu, Y. Jeong et al., "Redox-responsive nanophotosensitizer composed of chlorin e6-conjugated dextran for photodynamic treatment of colon cancer cells," Journal of Nanomaterials, vol. 2016, Article ID 4075803, 12 pages, 2016.

[14] E. S. Lee, K. Na, and Y. H. Bae, "Polymeric micelle for tumor pH and folate-mediated targeting," Journal of Controlled Release, vol. 91, no. 1-2, pp. 103-113, 2003.

[15] E. S. Lee, Z. Gao, and Y. H. Bae, "Recent progress in tumor $\mathrm{pH}$ targeting nanotechnology," Journal of Controlled Release, vol. 132, no. 3, pp. 164-170, 2008.

[16] Z. Liu, S. Tang, Z. Xu et al., "Preparation and in vitro evaluation of a multifunctional iron silicate@liposome nanohybrid for pH-sensitive doxorubicin delivery and photoacoustic imaging," Journal of Nanomaterials, vol. 2015, Article ID 541763, 13 pages, 2015.

[17] C. Ding, J. Gu, X. Qu, and Z. Yang, "Preparation of multifunctional drug carrier for tumor-specific uptake and enhanced intracellular delivery through the conjugation of weak acid labile linker," Bioconjugate Chemistry, vol. 20, no. 6, pp. 11631170, 2009.

[18] J. Gu, W.-P. Cheng, J. Liu et al., "pH-triggered reversible 'stealth' polycationic micelles," Biomacromolecules, vol. 9, no. 1, pp. 255$262,2008$.

[19] W. Park, S.-J. Park, and K. Na, “The controlled photoactivity of nanoparticles derived from ionic interactions between a water soluble polymeric photosensitizer and polysaccharide quencher," Biomaterials, vol. 32, no. 32, pp. 8261-8270, 2011.

[20] H. Park and K. Na, "Conjugation of the photosensitizer Chlorin e6 to pluronic F127 for enhanced cellular internalization for photodynamic therapy," Biomaterials, vol. 34 , no. 28, pp. 69927000, 2013.

[21] W. Park, S.-J. Park, and K. Na, "Potential of self-organizing nanogel with acetylated chondroitin sulfate as an anti-cancer drug carrier," Colloids and Surfaces B: Biointerfaces, vol. 79, no. 2, pp. 501-508, 2010.

[22] J. Aguiar, P. Carpena, J. A. Molina-Bolívar, and C. C. Ruiz, "On the determination of the critical micelle concentration by the pyrene 1:3 ratio method," Journal of Colloid and Interface Science, vol. 258, no. 1, pp. 116-122, 2003.
[23] W. Park, K. S. Kim, B.-C. Bae, Y.-H. Kim, and K. Na, "Cancer cell specific targeting of nanogels from acetylated hyaluronic acid with low molecular weight," European Journal of Pharmaceutical Sciences, vol. 40, no. 4, pp. 367-375, 2010.

[24] J. Donoso, F. Muñoz, A. García Del Vado, G. Echevarría, and F. García Blanco, "Study of the hydrolysis and ionization constants of Schiff base from pyridoxal $5^{\prime}$-phosphate and n-hexylamine in partially aqueous solvents. An application to phosphorylase b," Biochemical Journal, vol. 238, no. 1, pp. 137-144, 1986.

[25] B.-C. Bae and K. Na, "Self-quenching polysaccharide-based nanogels of pullulan/folate-photosensitizer conjugates for photodynamic therapy," Biomaterials, vol. 31, no. 24, pp. 6325-6335, 2010.

[26] F. M. Veronese and G. Pasut, "PEGylation, successful approach to drug delivery," Drug Discovery Today, vol. 10, no. 21, pp. 14511458, 2005.

[27] R. B. Greenwald, Y. H. Choe, J. McGuire, and C. D. Conover, "Effective drug delivery by PEGylated drug conjugates," Advanced Drug Delivery Reviews, vol. 55, no. 2, pp. 217-250, 2003.

[28] H. Yim, W. Park, D. Kim, T. M. Fahmy, and K. Na, "A selfassembled polymeric micellar immunomodulator for cancer treatment based on cationic amphiphilic polymers," Biomaterials, vol. 35, no. 37, pp. 9912-9919, 2014.

[29] D. Fischer, Y. Li, B. Ahlemeyer, J. Krieglstein, and T. Kissel, "In vitro cytotoxicity testing of polycations: influence of polymer structure on cell viability and hemolysis," Biomaterials, vol. 24, no. 7, pp. 1121-1131, 2003. 

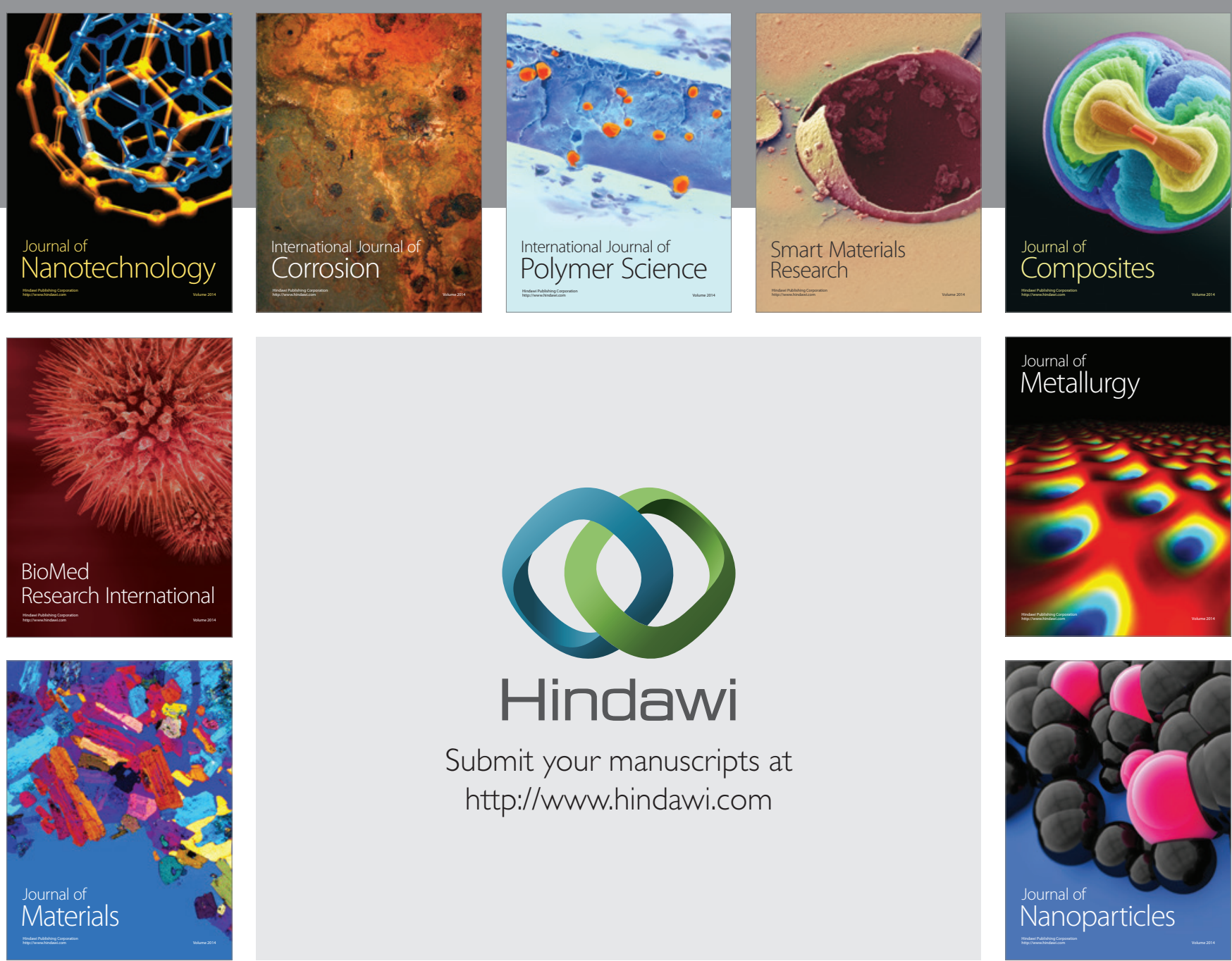

\section{Hindawi}

Submit your manuscripts at

http://www.hindawi.com

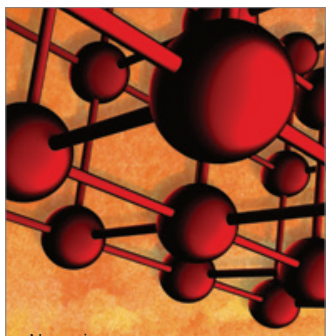

Materials Science and Engineering
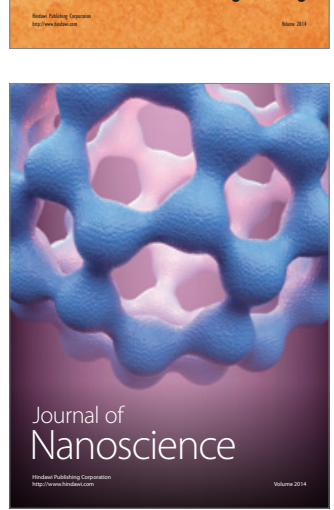
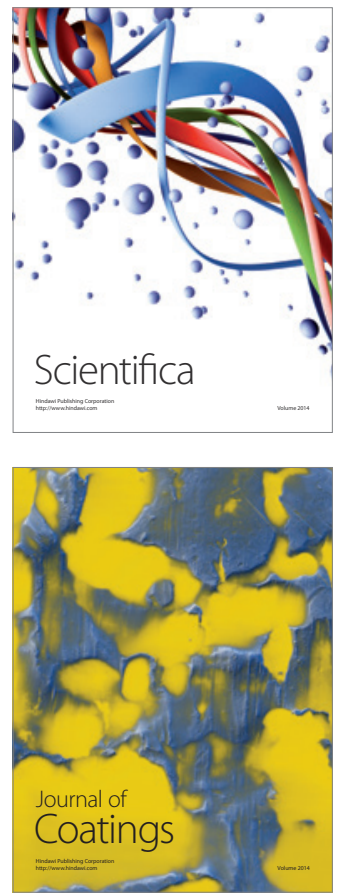
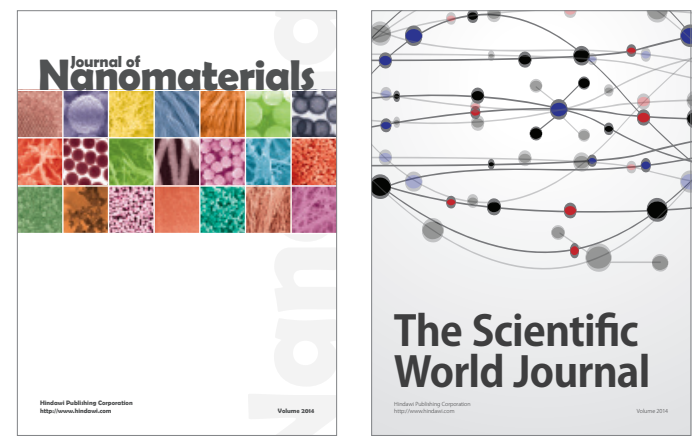

The Scientific World Journal
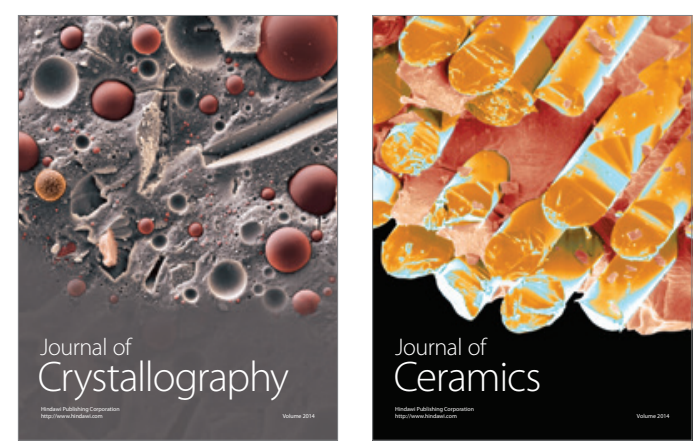
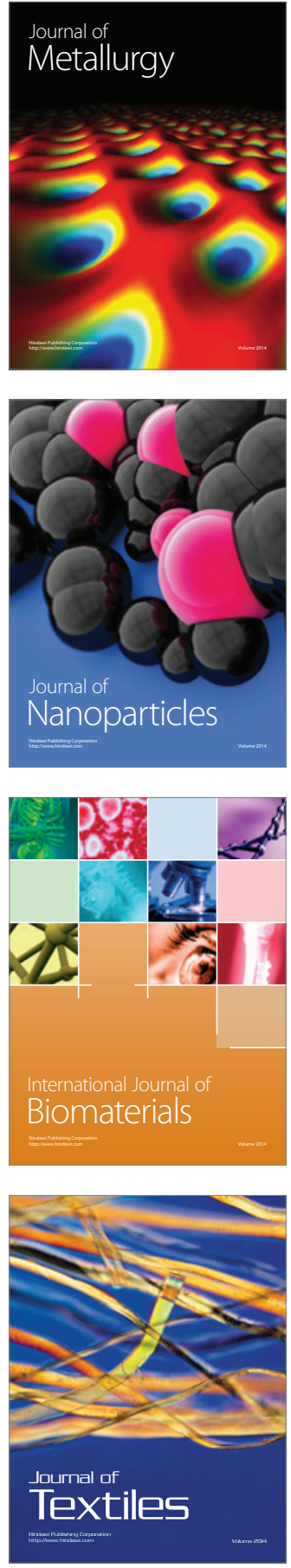